\title{
Rupture directivity and source-process time of the September 20, 1999 Chi-Chi, Taiwan, earthquake estimated from Rayleigh-wave phase velocity
}

\author{
Ruey-Der Hwang ${ }^{1}$, Guey-Kuen $\mathrm{Yu}^{1}$, and Jeen-Hwa Wang ${ }^{2}$ \\ ${ }^{1}$ Institute of Geophysics, National Central University, Chung-Li, 320 Taiwan \\ ${ }^{2}$ Institute of Earth Sciences, Academia Sinica, P.O. Box 1-55, Nankang, Taipei, 115 Taiwan
}

(Received September 25, 2000; Revised July 30, 2001; Accepted July 30, 2001)

\begin{abstract}
Rayleigh-wave phase-delay differences between the main shock and its aftershocks, regarded as source duration varying with azimuth, at period range of $60 \sim 120$ seconds, were used to rapidly determine the rupture directivity and the source-process time of the 1999 Chi-Chi, Taiwan, earthquake. Results show that the earthquake faulting exhibits an obvious directivity with an optimal rupture azimuth of about $42^{\circ}$ in the northeast direction. The earthquake has an average source-process time at $40.6 \pm 0.5 \mathrm{sec}$ and a rupture length of $77.0 \pm 3.6 \mathrm{~km}$ during rupture. In addition, periods at nodes of amplitude spectra of the main shock were adopted to estimate the rupture time, to be about $34.0 \pm 0.7 \mathrm{sec}$; the rise time of $6.7 \pm 0.6 \mathrm{sec}$, and a slightly slow rupture velocity, $2.27 \pm 0.15$ $\mathrm{km} / \mathrm{sec}$, were also obtained. According to Savage's suggestion, the rupture width of the fault was estimated to be $30.5 \pm 4.5 \mathrm{~km}$. Relying on these estimated faults parameters, we calculate the average static stress drop of about 56 bars, lying in between the stress drop of interplate earthquakes and intraplate earthquakes. We also infer the average dynamic stress drop of 52 bars based on Brune's theory. By the comparison of the two stress-drops, an Orowan's stress model or a stress model of frictional overshot is probably appropriate to describe the rupture behavior of the earthquake. The radiated seismic energy, then, was estimated at about $1.9 \times 10^{23} \mathrm{ergs}$, about 16 times larger than the value reported by the USGS.
\end{abstract}

\section{Introduction}

The Chi-Chi, Taiwan, earthquake, a shallow and lowangle thrust-faulting earthquake with $\mathrm{Ms}=7.6$ (USGS), occurred in central Taiwan on September 20, 1999. This was the most seriously disastrous earthquake for Taiwan within fifty years. The obvious surface rupture $(\sim 80 \mathrm{~km})$ and large crust deformation (vertical displacement of $1 \sim 8 \mathrm{~m}$ ) were generated during earthquake rupture (Ma et al., 1999; Wang et al., 2000). In accordance with source rupture inversion (Lee and Ma, 2000; Yagi and Kikuchi, 2001), the Chi-Chi earthquake ruptures from south to north and consists of several subevents with the largest one in the northern portion of the fault. Such an earthquake would cause asymmetrically azimuthal distribution of waveforms and have the observed seismic-wave travel-time delayed because of source finiteness.

Ben-Menahem (1961) first proposed a theory of finite moving source to account for the effect of rupture propagation on far-field seismograms. The effects on seismic waves will be observed in two ways: one is to produce the time delay in a certain direction of wave propagation, and the other is that amplitude spectra are weakened and then many nodes are generated (e.g. Ben-Menahem, 1961; Kanamori and Anderson, 1975). This theory has been widely applied to determine experimentally the fault length and the rupture velocity for large and great earthquakes (e.g. Ben-Menahem,

Copy right (C) The Society of Geomagnetism and Earth, Planetary and Space Sciences (SGEPSS); The Seismological Society of Japan; The Volcanological Society of Japan; The Geodetic Society of Japan; The Japanese Society for Planetary Sciences.
1961; Press et al., 1961; Filson and McEvilly, 1967). In recent years, the empirical Green's function analysis has been employed to investigate the source-process time and the rupture azimuth by means of surface wave data (e.g. Velasco et al., 1994). Furthermore, the experimental determination of the fault parameters is likely to cause an ambiguous estimation in the rupture length or the rupture velocity on account of the trade-off relation between these fault parameters. On the other hand, the empirical Green's function analysis has strict constraints including that focal mechanism and source depth of the main shock must be analogous to that of the aftershock, treated as an empirical Green's function; in addition, the locations of the two earthquakes must be quite close each other.

In this study, we calculate the phase-delay differences of fundamental-mode Rayleigh-wave, taken as the source duration varying with azimuth, between the main shock and its aftershocks so that the inconsistent locations and focal mechanisms between the main shock and its aftershocks are capable of being removed. Accordingly, following BenMenahem's theory, we can estimate rapidly and objectively the rupture directivity and fault parameters of the 1999 ChiChi, Taiwan, earthquake by using a least-squares technique.

\section{Data}

Long-period seismograms recorded at GSN (Global Seismic Network) stations with epicentral distances between $30^{\circ} \sim 90^{\circ}$ had been used in this study. Rayleigh wave trains were drawn out from the vertical-component seismograms 
(a)

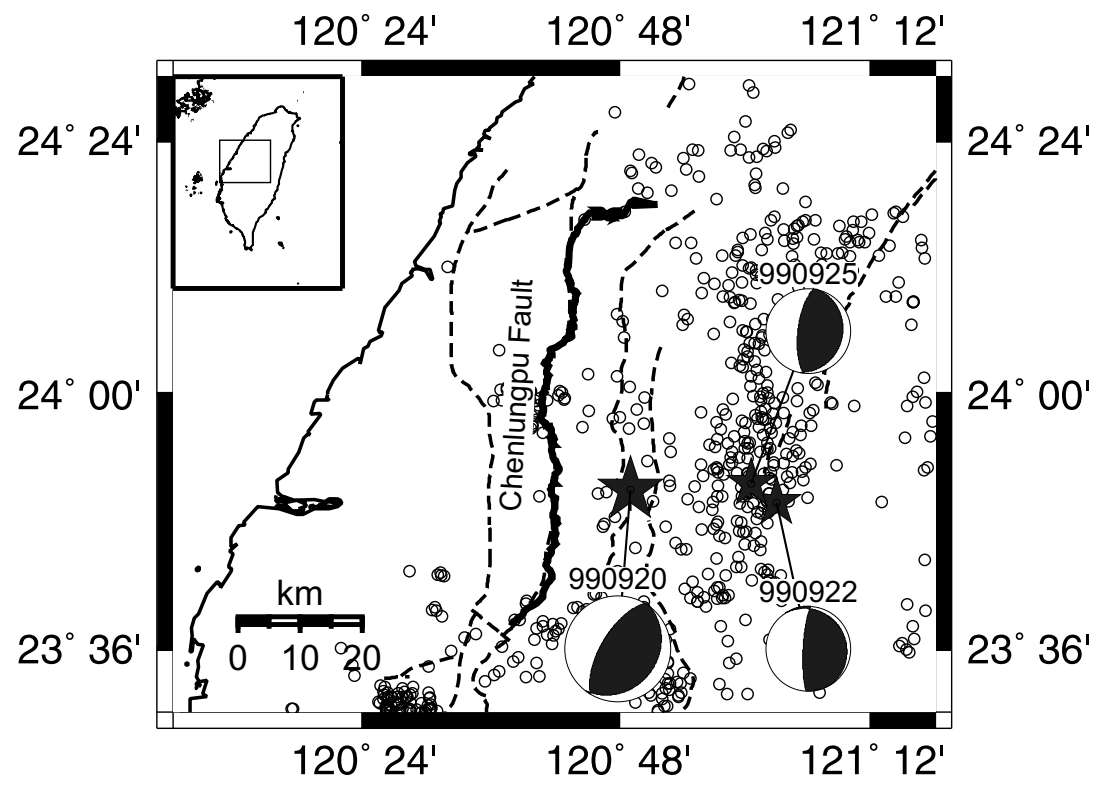

(b)

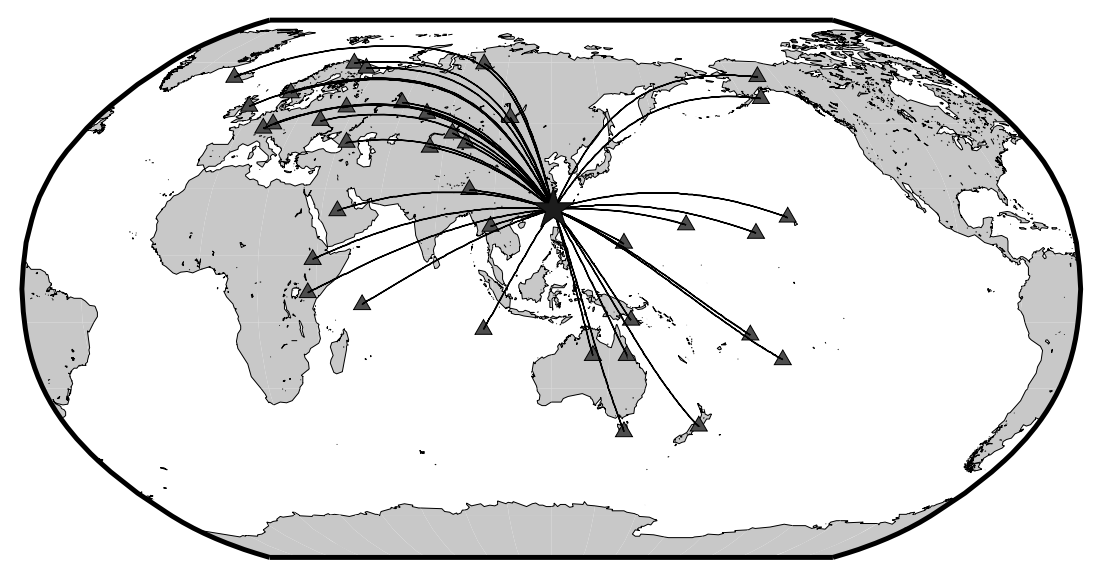

Fig. 1. (a) The large star represents the epicenter of the 1999 Chi-Chi, Taiwan, earthquake. Two small stars display the aftershocks, occurring in 09/22/1999 and 09/25/1999, respectively. Thick line denotes the surface rupture of the Chenlungpu fault, on which the main shock occurred. Dotted lines stand for the active faults in this region. Focal mechanisms, reported by the Harvard CMT group, are also shown. Aftershocks with $M_{L} \geq 3.0$ also plotted in the figure by open circles. (b) Map of the GSN stations (solid triangles) used in this study.

Table 1. Source parameters used in this study.

\begin{tabular}{|c|c|c|c|c|c|c|c|c|c|c|c|}
\hline \multirow[t]{2}{*}{ No. } & \multirow[t]{2}{*}{ Date } & \multicolumn{3}{|c|}{ Origin time (UT) } & \multicolumn{2}{|c|}{ Location } & \multirow{2}{*}{$\begin{array}{c}\text { Depth } \\
(\mathrm{km})\end{array}$} & \multirow[t]{2}{*}{ Ms } & \multicolumn{3}{|c|}{ Fault plane solution } \\
\hline & & hr. & $\min$. & $\mathrm{sec}$ & & & & & Strike & $\operatorname{dip}$ & slip \\
\hline 1 & 1999 Sept. 20 & 17 & 47 & 15.9 & $120.82^{\circ} \mathrm{E}$ & $23.85^{\circ} \mathrm{N}$ & 8 & 7.7 & $37^{\circ}$ & $25^{\circ}$ & $96^{\circ}$ \\
\hline 2 & 1999 Sept. 22 & 00 & 14 & 40.8 & $121.05^{\circ} \mathrm{E}$ & $23.83^{\circ} \mathrm{N}$ & 26 & 6.4 & $327^{\circ}$ & $12^{\circ}$ & $55^{\circ}$ \\
\hline 3 & 1999 Sept. 25 & 23 & 52 & 49.5 & $121.01^{\circ} \mathrm{E}$ & $23.86^{\circ} \mathrm{N}$ & 17 & 6.4 & $12^{\circ}$ & $20^{\circ}$ & $95^{\circ}$ \\
\hline
\end{tabular}

*Both origin time and location are provided by the Central Weather Bureau (CWB), Taiwan. Fault plane solutions are published by the Harvard CMT group. The depth of the main shock is from the final report of the CWB. The depths of the two aftershocks are from the report of the Harvard CMT group.

with a group velocity range of $2.3 \sim 4.8 \mathrm{~km} / \mathrm{sec}$. Each seismogram was corrected for the instrumental response, filtered between $10 \sim 300$ seconds and tapered by a cosine function. For periods less than $60 \mathrm{sec}$, the effect of source finiteness from the main shock is likely to distort seismograms, and result in incorrect phase-velocity measurements. At periods greater than $120 \mathrm{sec}$, Rayleigh wave trains are interfered by noise with ease. For this reason, taking the 

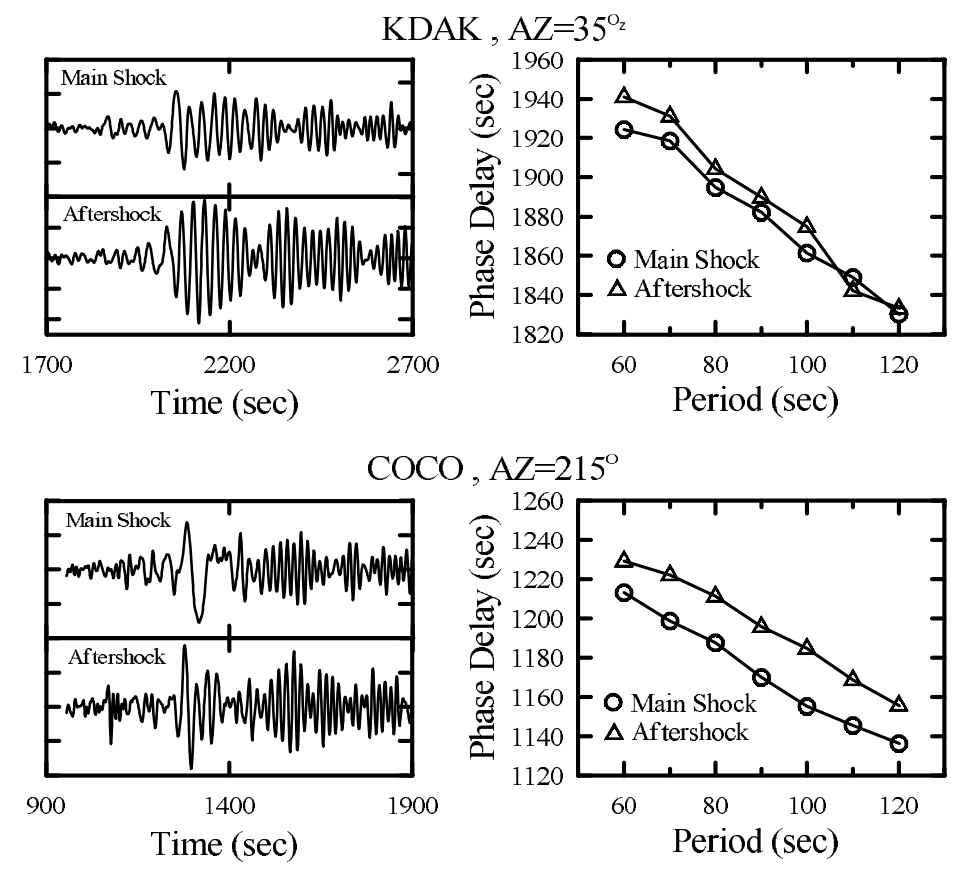

Fig. 2. Diagrams showing the vertical-component seismograms and the Rayleigh-wave phase delays between the main shock and $09 / 22 / 1999$ aftershock, observed at the stations KDAK and COCO for periods of $60 \sim 120$ seconds, respectively.

influence of the finite source and noise on seismic waves into consideration, we only adopted the observed data with period range of $60 \sim 120$ seconds to complete the phase velocity calculations. Figure 1(a) shows the locations and focal mechanisms of the main shock and its two large aftershocks. The source parameters of these earthquakes are listed in Table 1. As shown in Fig. 1(b), the stations used in this study reveal uniform azimuthal coverage around the epicenter. In Fig. 2, the seismograms of the main shock present the larger wave duration as compared with those of 09/22/1999 aftershock, especially for records at the station COCO, which departs from the rupture direction near to $180^{\circ}$. The phasedelay differences of Rayleigh waves observed at the station KDAK, which approaches the rupture direction, have the small deviations, whereas in opposite direction the phasedelay differences observed at the station $\mathrm{COCO}$ show larger values (Fig. 2). Such an obvious directivity provides us a good opportunity to study the rupture features for this earthquake.

\section{Method}

According to the theory of Ben-Menahem (1961), for an earthquake with a unilateral faulting, the phase delay due to the rupture propagation of source is defined as $\frac{1}{2}\left(\frac{L}{V_{r}}-\right.$ $\left.\frac{L}{C} \cos \Theta\right)$, where $L$ is the fault length, $V_{r}$ the rupture velocity and $C$ the average phase velocity in the source region. The azimuth, $\Theta$, is measured clockwise from the rupture direction of the fault to the station. Moreover, the dislocation source time function, often considered to be a ramp function with rise time, $\tau$, for far-field observations, will also make the observed phase velocity slow down. Thus, the sourceprocess time, $T_{\mathrm{SPT}}$, observed at a certain azimuth (corresponding to a given station), can be written in the following form.

$$
\begin{aligned}
T_{\mathrm{SPT}} & =\left(\frac{L}{V_{r}}-\frac{L}{C} \cos \Theta\right)+\tau \\
& =\left(\frac{L}{V_{r}}+\tau\right)-\frac{L}{C} \cos \Theta .
\end{aligned}
$$

In Eq. (1), there is a linear relationship between $T_{\mathrm{SPT}}$ and $\cos \Theta$. On azimuthal average, the whole source-process time is regarded as $\left(L / V_{r}+\tau\right)$, that is, the summation of the rupture time, $L / V_{r}$, and the rise time of source.

In fact, the source-process time for a given azimuth (or station) can be easily determined from the phase-delay differences of the Rayleigh-wave between the main shock and its aftershocks after some corrections have been made. In the following analysis, the phase velocities with periods of $60 \sim 120 \mathrm{sec}$ are first measured for the main shock and its two aftershocks by the single-station method (cf. Yu and Mitchell, 1979) after taking away initial phase of source (cf. Wang, 1981). In addition, the deviations in estimating the source-process time should be corrected owing to the source duration of the aftershocks and the inconsistent locations between the main shock and its aftershocks. Subsequently, the Rayleigh-wave phase-delay differences, $T_{\mathrm{PD}}$, corresponding to the source-process time, at a given station can be expressed as

$$
T_{\mathrm{PD}}=2\left(t_{m}-t_{a}\right)+S_{a}+2(\Delta d / C)
$$

where $t_{m}$ and $t_{a}$ are the average phase delays of Rayleighwave of the main shock and its aftershock, respectively. $S_{a}$, the source duration of aftershock, is taken as $8.0 \mathrm{sec}$ for earthquakes with $\mathrm{Ms}=6.4$ when the effects of the finite source on aftershocks are neglected, and $\Delta d$ is the difference of epicentral distance in $\mathrm{km}$ between the two earthquakes. $C$ is the average phase velocity in the source region, and plays a key role in estimating the rupture length 
as indicated in $L / C$ of Eq. (1). Because the dispersion in phase velocity is likely to obscure the estimation of the rupture length, we only adopted the phase velocities at period range of $60 \sim 120 \mathrm{sec}$, where the values are almost a constant (about $4.05 \mathrm{~km} / \mathrm{sec}$ ) for the continental structure. From Eqs. (1) and (2), $L / C$ and $\left(L / V_{r}+\tau\right)$ can be easily estimated by a least-squares fitting.

\section{Rupture Directivity, Source-Process Time and Rupture Length}

In Fig. 3, open circles and open triangles represent the average Rayleigh-wave phase-delay differences of the main shock to the 09/22/1999 and 09/25/1999 aftershocks, respectively. The rupture directivity is clearly exhibited with azimuth from Fig. 3, that is, there is the minimum time delay when $\Theta=0^{\circ}$; however, the maximum time delay appears at $\Theta=180^{\circ}$. The inset of Fig. 3 displays the optimal rupture azimuth of about $42^{\circ}$ in the northeast direction. This corresponds with the studies of the source rupture inversion (e.g. Yagi and Kikuchi, 2001) and the multiple events analysis (Kao and Chen, 2000). The best linear relation between $T_{\mathrm{SPT}}$ and $\cos \Theta$ is $T_{\mathrm{SPT}}=(40.6 \pm 0.5)-(19.0 \pm 0.9) \cos \Theta$ by using a least-squares method. From the slope of the regression line, the fault length is estimated to be about $77.0 \pm 3.6$ $\mathrm{km}$ when the average Rayleigh-wave phase velocity of 4.05 $\mathrm{km} / \mathrm{sec}$ in the source region is employed. This result agrees well with field observations (Ma et al., 1999; Wang et al., 2000). The estimated source-process time, $40.6 \pm 0.5 \mathrm{sec}$, for the Chi-Chi, Taiwan earthquake is in agreement with observations of the surface ground motions (Huang, 2000), and larger than that for similar-sized earthquakes, which have been routinely reported in several earthquake catalogs. This seems to suggest that the Chi-Chi, Taiwan, earthquake is likely to have a slow rupture behavior, on average, relative to similar-sized earthquakes. In general, rupture velocity is estimated from the whole source-process time and the rup-

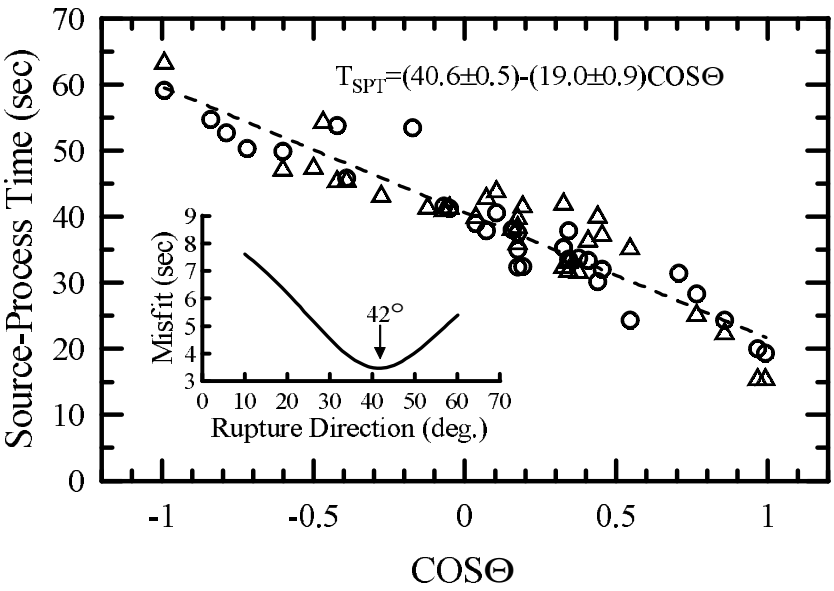

Fig. 3. The inset denotes the optimal rupture azimuth of $42^{\circ}$ determined from a minimum misfit. The plot of source-process time vs. $\cos \Theta$ presents a best linear relation based on the optimal rupture azimuth. Open circles show the phase-delay differences between the main shock and the 09/22/1999 aftershock; however, open triangles show the phase-delay differences between the main shock and the 09/25/1999 aftershock. The fitted equation is shown within the figure. ture length when the rise time of the earthquake is ignored. Hence, the rupture velocity is about $1.9 \mathrm{~km} / \mathrm{sec}$ for the ChiChi, Taiwan, earthquake; this value is a slightly lower than that for shallow earthquakes occurring at the other places. However, ignoring the effect of the rise time is likely to underestimate the rupture velocity.

\section{Rupture Velocity, Rise Time and Rupture Width}

In order to obtain more reasonable rupture velocity, we must divide the whole source process-time into the rupture time and the rise time (see Eq. (1)). It is difficult, however, to determine individually the rise time from Eq. (1). Hence, an additional viewpoint is necessary in this study for objectively deducing the rupture time. In frequency-domain, the source finiteness and the rise time can be expressed in terms of a sinc function, which make many nodes in amplitude spectra. Thus, the period of the first node generated by the source finiteness corresponds to $\left(\frac{L}{V_{r}}-\frac{L}{C} \cos \Theta\right)$, where notations are given in the previous section. From global observations, the rise time is generally less than 10 sec for earthquakes of such magnitude-sized Chi-Chi earthquake (Kanamori and Anderson, 1975; Geller, 1976). In other words, at periods lower than $10 \mathrm{sec}$, the period of the first node from the source finiteness is usually contaminated by the rise time. Accordingly, in this study, we estimated the rupture time by using the first node of the amplitude spectra at periods larger than 10 seconds. Two examples of
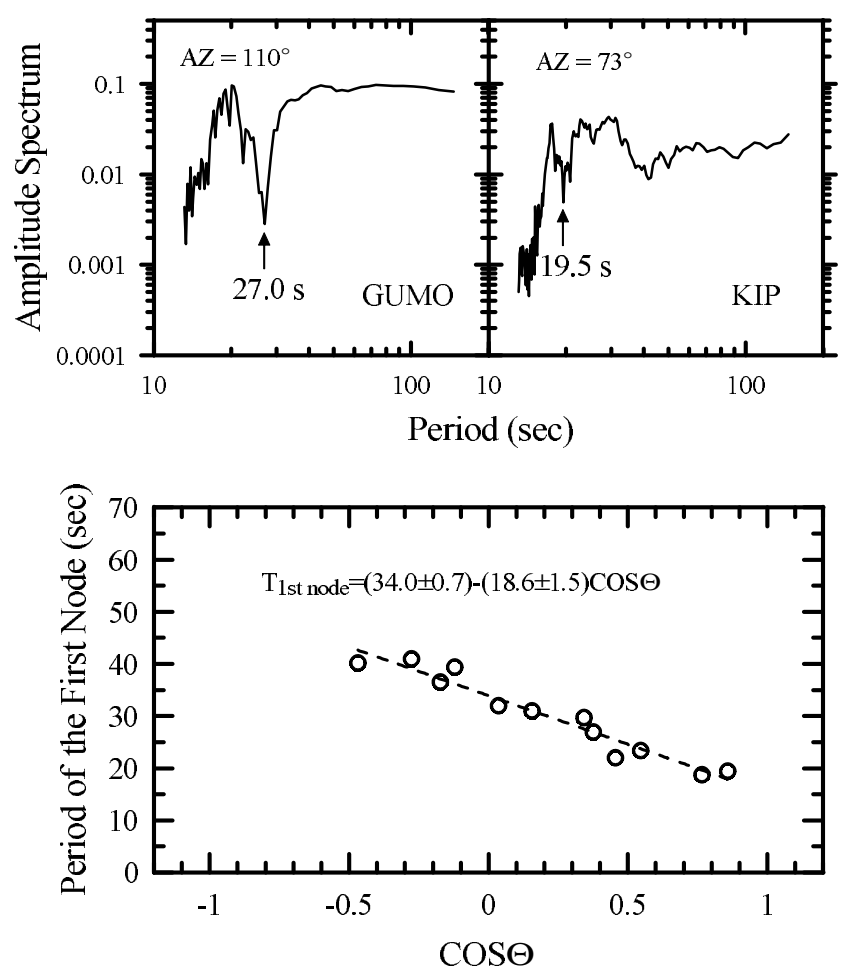

Fig. 4. Upper diagram shows two examples of amplitude spectra for the stations GUMO and KIP. Arrows designate the position of first node, and the corresponding periods are shown below. Lower diagram indicates the plot of period of the first node vs. $\cos \Theta$. A best linear relation from 12 data points is shown by a dotted line according to the optimal rupture azimuth (see Fig. 3). The fitted equation is also shown. 
the amplitude spectra with clear nodes are shown in Fig. 4. Although only 12 data points were used, the result shows a linear relation between the period of the first node and $\cos \Theta$. The corresponding directivity is also shown in lower diagram of Fig. 4. Because the slope of regression line for the lower diagram of Fig. 4 is in good agreement with that for Fig. 3, the consistency between the two figures leads to reliable determinations of the rupture time and the rupture velocity. From Fig. 4, the rupture time is estimated to be $34.0 \pm 0.7 \mathrm{sec}$. For this reason, the rupture velocity and the rise time can be determined simultaneously as $2.27 \pm 0.15$ $\mathrm{km} / \mathrm{sec}$ and $6.7 \pm 0.6 \mathrm{sec}$ for the earthquake. The rupture width is also estimated to be $30.5 \pm 4.5 \mathrm{~km}$ according as Savage (1972) suggested that $\tau_{r}=W / 2 V_{r}$, where $\tau_{r}$ is the rise time, $W$ the fault width and $V_{r}$ the rupture velocity.

\section{Discussion and Conclusion}

The estimated fault parameters listed in Table 2 show that the Chi-Chi, Taiwan, earthquake manifests a longer sourceprocess time as compared with those similar-sized earthquakes. The average rupture velocity is estimated at about 0.76 times the shear wave velocity (about $3.0 \mathrm{~km} / \mathrm{sec}$ in the upper crust), and is slightly lower, on average, than the common value for shallow earthquakes. Hence, the rupture length and the rupture velocity are the two main factors that control the source-process time during faulting and produce obvious rupture directivity. The estimated source-process time of about $41 \mathrm{sec}$ in this study agrees with Huang's observations (Huang, 2000). He used strong-motion data observed in Taiwan to reconstruct time-dependent spatial ground motions of the 1999 Chi-Chi, Taiwan, earthquake, and indicated that seismic energy radiation from the source rupture was entirely released within $42 \mathrm{sec}$ after the start of the rupture.

From Fig. 3, the estimated rupture direction was $42^{\circ}$ toward the northeast. In this study, we also determined the rupture direction only using the main shock but not aftershocks corrections. In Fig. 4, the nodes are purely picked from the spectra of the main shock, and then used to estimate the rupture direction as in Fig. 3. The rupture direction estimated from Fig. 4 is $38^{\circ}$ toward the northeast, which is consistent with the estimate from Fig. 3. This result indicates that the fault ruptures along the fault plane from a shallower depth at the southern segment of the fault to a deeper depth at the northern portion of the fault. The rupture direction on the fault plane is finally projected onto the earth surface and result in a value of $42^{\circ}$ measured clockwise from the north.

Table 2. Fault parameters estimated in this study.

\begin{tabular}{ll}
\hline Rupture length of earthquake fault & $77.0 \pm 3.6 \mathrm{~km}$ \\
Rupture width of earthquake fault & $30.5 \pm 4.5 \mathrm{~km}$ \\
Average source-process time & $40.6 \pm 0.5 \mathrm{sec}$ \\
Rupture azimuth & $42^{\circ}$ \\
Rupture time & $34.0 \pm 0.7 \mathrm{sec}$ \\
Rise time & $6.7 \pm 0.6 \mathrm{sec}$ \\
Rupture velocity & $2.27 \pm 0.15 \mathrm{~km} / \mathrm{sec}$ \\
\hline
\end{tabular}

Although this result is different from the other source models showing a north-south direction rupture (Lee and Ma, 2000; Ma et al., 2000), our result seems to be in agreement with the recent study of Yagi and Kikuchi (2001). Yagi and Kikuchi (2001) adopted the source duration of about $40 \mathrm{sec}$ to invert the slip distribution of the earthquake by joint inversion of strong-motion data and teleseismic data and shown an extensive and a deeper rupture along the fault plane, especially on the northern part of the fault. The rupture depths vary from about $20 \mathrm{~km}$ at the southern portion of the fault to about $50 \mathrm{~km}$ at the northern one along the fault plane. Discrepancies between these source models are mainly from the usage of different source duration and inversion methods. A shorter source-duration used in the study of source rupture process might cause the slip distribution concentrated on the shallow depth. Huang (2000) reported that the whole energy release of the earthquake is about $42 \mathrm{sec}$, consistent with our study. Hence, we consider that the longer source duration used to invert the source rupture is reasonable. In a recent study, Huang and Wang (2001) stated that the scaling of power spectra of near-field seismograms of the earthquake increasingly vary from south to north. This seems to imply that a deeper rupture would take place at the northern part of the fault than at the southern one, and then the whole rupture with the northeast direction during faulting would be probably generated. The surface breaks of the Chelungpu fault, on which the Chi-Chi, Taiwan, earthquake occurred, almost exhibit north-south orientation, but the geometry of the fault under the ground is not known. Recently, Ji et al. (2001) used a model with multi-fault segments instead of a single fault model to invert the slip distribution of the Chi-Chi earthquake, and concluded that all contributions from the multi-fault portions would result in a northeast rupture direction, incompatible with the orientation of the Chenlungpu fault. Consequently, our results apparently represent the whole feature of the earthquake rupture from surface-wave observations.

A rise time of $6.7 \pm 0.6 \mathrm{sec}$ for the Chi-Chi earthquake is larger than that for earthquakes with the same magnitude (Kanamori and Anderson, 1975; Geller, 1976). This result is comparable to a recent study of Huang et al. (2000), in which the rise time of the northern rupture of the fault was estimated to be $5 \mathrm{sec}$. The rupture length is about 2.5 times the rupture width, which slightly departs from the geometrical similarity of the fault plane. The rupture length and rupture width of a large earthquake are often determined by the distributions of aftershocks, but for the Chi-Chi earthquake, the aftershocks are almost located on the east of the fault so that it is difficult to estimate the rupture length and rupture width (Fig. 1(a)). Therefore, the main rupture area estimated by aftershocks would probably result in overestimation and then presumably give a lower stress drop (e.g. Gibowicz, 1986).

An average dislocation of $3.5 \pm 0.7$ meters is estimated from the seismic moment $M_{O}=2.4 \times 10^{27}$ dyne-cm (USGS), the rigidity, $\mu=3.0 \times 10^{11}$ dyne- $\mathrm{cm}^{-2}$ and the area of the fault, $A$, in light of $M_{O}=\mu A D$ (Aki, 1966). The area of the fault can be determined by the estimated rupture length and rupture width listed in Table 2. Thus the average static stress drop, $\Delta \sigma$, is inferred as 56 bars, 
which is different from the report of EIC Seismological Note in Japan ( $\sim 33$ bars). This value seems to lie in between values for interplate earthquakes ( $\sim 30$ bars) and intraplate earthquakes ( $\sim 100$ bars) (Kanamori and Anderson, 1975). This might be possibly related to the particular tectonic feature in Taiwan. The average particle velocity of the earthquake is about $52 \mathrm{~cm} / \mathrm{sec}$, which is near common observations for large earthquakes (Kanamori, 1994). Following Brune's theory (Brune, 1970), we determine the average dynamic stress drop, $\Delta \sigma_{d}$, to be about 52 bars, which is almost the same as the average static stress drop. As a result, the Orowan's model (Orowan, 1960), in which the dynamic stress is equal to the final stress, is likely to describe the rupture behavior of the earthquake. However, since the average dynamic stress drop is somewhat lower than the average stress drop, the stress model of frictional overshoot, in which the dynamic stress is smaller than the final stress, provides an alternative interpretation to the rupture of the Chelungpu fault, on which the Chi-Chi, Taiwan, earthquake occurred. By systematically calculating the source parameters of the earthquake, an estimate of the radiated seismic energy, $E_{S}$, according to the formula: $E_{S}=M_{O}\left(2 \Delta \sigma_{d}-\Delta \sigma\right) / 2 \mu$ (Kanamori and Heaton, 2000), can be calculated. Then, the radiated seismic energy is calculated to be $1.9 \times 10^{23}$ ergs, compared with $1.0 \times 10^{24}$ ergs estimated by Mori et al. (2000) using near-field seismograms and about 16 times the value given by the USGS $\left(\sim 1.2 \times 10^{22} \mathrm{ergs}\right)$. Moreover, the $E_{S} / M_{O}$ ratio (about $8.0 \times 10^{-5}$ ) is also quite close to the global average observations $\left(\sim 5.0 \times 10^{-5}\right)$ (Vassiliou and Kanamori, 1982). Through such this work, we can rapidly estimate the fault parameters for a unilateral faulting earthquake from phase-delay differences of Rayleigh waves.

Acknowledgments. We would like to express our gratitude to IRIS for providing us with the GSN data. The authors also thank the two anonymous reviewers for their critical review. This study was financially supported by a grant from the National Science Council, R.O.C. under No. NSC89-2811-M-008-0024 and NSC892921-M-008-002-EAF.

\section{References}

Aki, K., Generation and propagation of $\mathrm{G}$ waves from the Niigata earthquake of June 16, 1964, 2, Estimation of earthquake moment, released energy, and stress-strain drop from the $\mathrm{G}$ wave spectrum, Bull. Earthq. Res. Inst. Tokyo Univ., 44, 73-88, 1966.

Ben-Menahem, A., Radiation of seismic surface-waves from finite moving sources, Bull. Seism. Soc. Am., 51, 401-435, 1961.

Brune, J. N., Tectonic stress and the spectra of seismic shear wave from earthquakes, J. Geophys. Res., 75, 4997-5009, 1970.

Filson, J. and T. V. McEvilly, Love spectra and the mechanism of the 1966 Parkfield sequence, Bull. Seism. Soc. Am., 57, 1245-1257, 1967.

Geller, R. J., Scaling relations for earthquake source parameters and magnitudes, Bull. Seism. Soc. Am., 66, 1501-1523, 1976.

Gibowicz, S. J., Physics of fracturing and seismic energy release: A review, PAGEOPH, 124, 611-658, 1986.

Huang, B.-S., Two-dimensional reconstruction of the surface group mo- tions of an earthquake: the September 21, 1999, Chi-Chi, Taiwan earthquake, Geohpys. Res. Lett., 27, 3025-3028, 2000.

Huang, M.-W. and J.-H. Wang, Scaling of power spectra of near-field seismograms of the 1999 Chi-Chi, Taiwan, Earthquake, Geophys. Res. Lett., 2001 (submitted).

Huang, B.-S., K.-C. Chen, W.-G. Huang, J.-H. Wang, T.-M. Chang, R.D. Hwang, H.-C. Chiu, and C.-C. Tsai, Characteristics of strong ground motion across a thrust fault tip from the September 21, 1999, Chi-Chi, Taiwan earthquake, Geophys. Res. Lett., 27, 2729-2732, 2000.

Ji, C., D. V. Helmberger, T.-R. A. Song, K-.F. Ma, and D. J. Wald, The 1999 Chi-Chi, Taiwan, earthquake: A massive wedge shaped heave, Geophys. Res. Lett., 2001 (submitted).

Kanamori, H., Mechanics of earthquakes, Annu. Rev. Earth Planet. Sci., 22 207-237, 1994.

Kanamori, H. and D. L. Anderson, Theoretical basis of some empirical relation in seismology, Bull. Seism. Soc. Am., 65, 1073-1095, 1975.

Kanamori, H. and T. H. Heaton, Microscopic and macroscopic physics of earthquakes, in GeoComplexity and the Physics of Earthquakes, edited by J. B. Rundle et al., 296 pp., Geophysical Monograph Series, AGU, 2000 .

Kao, H. and W.-P. Chen, The Chi-Chi earthquake sequence: Active, out-ofsequence thrust faulting in Taiwan, Science, 288, 2346-2349, 2000.

Lee, S.-J. and K.-F. Ma, Rupture process of the 1999 Chi-Chi, Taiwan, earthquake from the inversion of teleseismic data, TAO, 3, 591-608, 2000.

Ma, K.-F., C.-T. Lee, Y.-B. Tsai, T.-C. Shin, and J. Mori, The Chi-Chi, Taiwan earthquake: Large surface displacements on an inland thrust fault, EOS Trans. American Geophysical Union, 80, 605-611, 1999.

Ma, K.-F., T.-R. A. Song, S.-J. Lee, and H.-I. Wu, Spatial slip distribution of the September 20, 1999, Chi-Chi, Taiwan, Earthquake (Mw 7.6) Inverted from telesemic data, Geophys. Res. Lett., 27, 3417-3420, 2000.

Mori, J., K.-F. Ma, and T.-R. A. Song, Dynamic stress drop estimates for the 1999 Chi-Chi Taiwan earthquake: Indications of low dynamic friction, EOS Trans. American Geophysical Union 2000 WPGM, 81, 140, 2000.

Orowan, E., Mechanism of seismic faulting, Geol. Soc. Am. Mem., 79, 323 $345,1960$.

Press, F., A. Ben-Menahem, and M. N. Toksöz, Experimental determination of earthquake fault length and rupture velocity, J. Geophys. Res., 66, 3471-3485, 1961.

Savage, J. C., Relation of corner frequency to fault dimension, J. Geophys. Res., 77, 3788-3795, 1972.

Vassiliou, M. S. and H. Kanamori, The energy release in earthquakes, Bull. Seism. Soc. Am., 72, 371-387, 1982.

Velasco, A. A., C. J. Ammon, T. Lay, and J. Zhang, Imaging a slow bilateral rupture with broadband seismic waves: The September 2, 1992 Nicaraguan tsunami earthquake, Geophys. Res. Lett., 21, 2629-2632, 1994

Wang, C. Y., Wave theory for seismogram synthesis, 235 pp., Ph.D. Dissertation, Saint Louis University, 1981.

Wang, J.-H., R.-D. Hwang, K.-C. Chen, B.-S. Huang, C.-H. Chiu, C.-C. Tsai, W.-G. Huang, and T.-M. Chang, The Ms 7.6 Chi-Chi, Taiwan, earthquake of September 20, 1999, Proceed. Int. Workshop on Seismotectonics at the Subduction Zone, Tsukuba, Japan, 351-360, 2000.

Yagi, Y. and M. Kikuchi, Spatiotemporal distribution of source rupture process for 1999 Chi-Chi, Taiwan earthquake. Posted on http:// wwweic.eri.u-tokyo.ac.jp/yuji/taiwan/taiwan.html, 2001.

Yu, G. K. and B. J. Mitchell, Regionalized shear velocity models of the Pacific upper mantle from observed Love and Rayleigh wave dispersion, Geophys. J. R. astr. Soc., 57, 311-341, 1979.

R.-D. Hwang (e-mail: red@ftp1.gep.ncu.edu.tw), G.-K. Yu, and J.-H. Wang 